\title{
Social geographies of African American men who have sex with men (MSM): a qualitative exploration of the social, spatial and temporal context of HIV risk in Baltimore, Maryland
}

\author{
KE Tobin ${ }^{\mathrm{a}}$, M Cutchin $^{\mathrm{b}}$, CA Latkin ${ }^{\mathrm{c}}$, and LM Takahashid \\ aKarin E. Tobin, Department of Health, Behavior and Society, Bloomberg School of Public Health, \\ Johns Hopkins University, 2213 McElderry Street, Second floor, Baltimore, Maryland, 21205, \\ USA, 410-502-5386, 410-502-5385 (fax), ktobin@jhsph,edu \\ bOccupational Science \& Occupational Therapy, University of North Carolina at Chapel Hill, CB \\ \#7122, Bondurant Hall, Suite 2050, Chapel Hill, NC 27599-7122, USA, mcutchin@med.unc.edu \\ 'Department of Health, Behavior and Society, Bloomberg School of Public Health, Johns Hopkins \\ University, 615 North Wolfe Street, room 737, Baltimore, Maryland, 21205, USA, \\ clatkin@jhsph.edu
}

dDepartments of Urban Planning and Asian American Studies, University of California Los Angeles, Box 951656, Los Angeles, CA 90095-1656, USA, takahash@ucla.edu

\section{Introduction}

Men who have sex with men (MSM) continue to represent a major proportion of new HIV infections in the United States (Finlayson et al. 2011). Strong empirical evidence indicates the main risk factors associated with HIV infection among MSM are unprotected anal intercourse, multiple sexual partners, and drug and alcohol use (Koblin et al. 2006). Drug and alcohol use, in particular, are associated with exchanging sex for money or drugs and lower condom use (Gorbach et al. 2009, Rhodes et al. 1999, Colfax et al. 2005, Semple et al. 2010, Stall et al. 2003, Crosby et al. 1996, Reisner et al. 2010). Research on risk environments (Rhodes 2009), such as bars/clubs, bathhouses, and community events (e.g. Gay Pride) has highlighted the importance of considering the social, spatial and temporal context of sexual mixing patterns, sex under the influence, and exchanging sex for money/ drugs (Rhodes et al. 1999, Colfax et al. 2005, Mimiaga et al. 2010).

African-American MSM (AA MSM) are disproportionately affected compared to their White counterparts despite findings that AA MSM are behaviorally less risky (Sifakis et al. 2007, Millett et al. 2007, Sifakis et al. 2010, Magnus et al. 2010, German et al. 2011). The causal factors for this disparity are likely related to the social, spatial and temporal contexts that may foster HIV risk for AA MSM (Frye et al. 2006, Egan et al. 2011, Mills et al. 2001). We suggest that what has been lacking in current approaches to research on HIV prevention and disparities is attention to where individuals spend their time and their movements between various social and/or risk environments. We are especially interested in daily

(C) 2013 Elsevier Ltd. All rights reserved.

Correspondence to: KE Tobin.

Publisher's Disclaimer: This is a PDF file of an unedited manuscript that has been accepted for publication. As a service to our customers we are providing this early version of the manuscript. The manuscript will undergo copyediting, typesetting, and review of the resulting proof before it is published in its final citable form. Please note that during the production process errors may be discovered which could affect the content, and all legal disclaimers that apply to the journal pertain. 
routines (the activities that individuals engage in regularly) and paths (the temporal and spatial context within which their activities occur) as they constitute socio-behavioral patterns that are predictable and regular (Zisberg et al. 2007, Pred 1977b) and that are shaped by social networks and access to resources (Gilbert 1998). Routines may also reflect and reinforce the frequenting of certain risk environments, such as bars, that have specific social norms that elevate risk, such as acceptability of substance use and multiple sexual partners.

We argue, in this paper, that using a daily routines and path approach, informed by Hagerstränd's classic time-geography framework (Pred 1977a), we are able to study how place and social networks operate together to shape HIV risk. There is a distinct need for investigations of AA MSM behavior within socio-spatial contexts to enable researchers to clarify the causal factors for disparities and to design more effective intervention programs. This study sought to address this gap by exploring the routines and paths of a sample of AA MSM in Baltimore, Maryland and how these facilitate or constrain HIV risk.

\section{Methods}

\section{Study Context}

Baltimore is one of the most sexually transmitted disease burdened cities in the US with high rates of Syphilis, Gonorrhea, and Chlamydia (Centers for Disease Control and Prevention 2011, Centers for Disease Control and Prevention 2000). The majority of the population (64\% of 621,000 people (U.S. Census Bureau 2012)) is African American, the unemployment rate is $12 \%$, and $21 \%$ live below the poverty level. There is significant racial residential segregation, such that the Northern section of the city is majority White and the Western and Eastern sections are predominantly African American (Jacobson 2007). Higher rates of poverty, crime and drug use correspond with the Western and Eastern sections of the city. In the center of the city is a mixed residential and commercial neighborhood where the majority of gay bars, clubs and restaurants are located. The racial composition of this neighborhood is predominantly White, however, the one African American owned gay club is also located in this neighborhood. Within this neighborhood is also a public area known for male sex exchange activities. To the West of this neighborhood is a public park that is well-known for sexual hook-ups among MSM.

\section{Study Population}

Participants for this study were recruited using street-based outreach to businesses, cafes/ bars known to have AA MSM patronage and word-of-mouth referral. Interested participants were screened by trained research staff or the lead author via the phone or in person at a community-based research clinic. Inclusion criteria were self reported: 1) age 18 years old or older, 2) African American race/ethnicity, 3) identify as male, 4) sex with another male in the prior 6 months, and 5) reside in Baltimore City, Maryland. Data collection occurred between October 2010 and March 2012.

The lead author conducted all in-depth interviews in a private office in a research clinic located in a mixed residential and commercial neighborhood. As the lead author was not of the same race or gender of the participants, she introduced herself as a community-based researcher who has been conducting research in Baltimore focused on HIV prevention for the past 12 years, and was asking for their expertise and opinions about how to develop programs that were relevant to their lives. Participants were told that the purpose of the study was to learn about places in Baltimore that are important to them and their perspectives about HIV prevention. After providing written informed consent, the in-depth interview lasted between 60-90 minutes. All interviews were audio-recorded with 
participant consent. Participants received $\$ 50$ at the end of the interview. This research was reviewed and approved by the Johns Hopkins Bloomberg School of Public Health IRB.

\section{Topics of the In-depth Interview}

To begin the interview, participants were asked to report their age, employment and relationship status (e.g. single, partnered). They were asked to describe their typical day, including activities, location of activities, and individuals with whom they interact. As the participant described these, the interviewer drew a map, depicting his movement throughout the city. Participants were asked to verify these routes as they were drawn. These maps were used by the lead author to facilitate a dialog with the participant about the degree of movement or constraint in the participants' path. They were also asked to describe people in their social network, specifically, their social support network, sexual partners, people they used drugs with, and AA MSM peers. If men described HIV risk behaviors, they were probed to elaborate on the regularity of these behaviors. Participants were then asked to "describe places that were central or meaningful for African American men who have sex with men in Baltimore". Their responses were further probed to learn about the location, physical characteristics, types of people who frequent the place, and aspects of the place (physical characteristics and/or social characteristics) that made it meaningful. We did not ask the participants to choose a sexual identity category (e.g. homosexual/heterosexual or gay identified) but we did ask them to describe the extent to which people in their social networks knew that they had sex with men.

\section{Analysis}

Immediately after each interview, a detailed narrative synopsis was written by the lead author, summarizing the profile of each study participant in terms of his daily routine, daily path, social network and HIV risk. Pseudonyms and initials of individuals were substituted to protect the identity of places and social network members. Recordings of the interviews were reviewed, transcribed and coded by the lead author. Based on a consensus approach, after discussions and review of codes and emerging themes by co-authors, revision and further comparative analysis of themes by the lead author, both within and between cases, resulted in the findings discussed below.

\section{Findings}

Twenty in-depth interviews were completed. On average, participants were 34 years old (ranged from 21-50 years). Profiles of participants are presented in Table 1. Half of the sample was unemployed. Nine men were employed in full or part-time jobs and one participant was enrolled as a full-time student in college. From an initial review of the transcripts, two dimensions appeared to be particularly important for these AA MSM in terms of their daily routines and paths: employment/student status and addiction. Regular and planned paths and routines were described by men who were employed or in school, while less routinized paths were characterized by men who were unemployed or addicted to drugs or alcohol. Addiction was defined as daily use of alcohol or any substance such as marijuana or crack cocaine.

\section{Regular and Planned Routines and Paths: Employment or School}

Men who were employed or enrolled as students in college described regular and planned routines throughout the day. Their paths included travel from home to place of work/school, where substantial time was spent (5-9 hours), then returning to home. The focus of their activities was their job/studies, with social interactions limited to co-workers/fellow students and friends. Consequently, these paths/routines generally excluded places, activities or 
people who were engaged in sexual behavior or drug use and thus, in effect, constrained HIV risk. One participant explained:

I wake up (in my house), I smoke a cigarette and have a cup of coffee and sometimes but not all of the time I check my blood sugar, I take my medicine. Maybe before I do that I let the dogs out, I'll go back upstairs and coffee and cigarettes, I feed my dogs and myself - my partner is gone by then so it's really brief with us, we may share a cup of coffee and then he is out of the door so I'm there to take care of me and the dogs and then if it's a workday then I am preparing myself for work, because I work two 10 hours days. I leave home go to work and then usually come home and go to bed. Depending on how hungry we are I may stop on the way home and pick up something to eat. Last night I came home, had something to drink and ate a candy bar from work and everyone was in and ready for bed. But if I'm not working then I'm paying bills, making sure everything is there for the house, grocery shopping. (P2)

"Home" was described as a place of acceptance or belonging for themselves and their friends and a space of control.

We have our friends over. My yard is made for entertaining so we get together for cookouts - I have friends from other areas that we invite over because you're more in control and you can keep them safe. (P2)

Gay bars/clubs were depicted as places with both positive and negative attributes. Sometimes, gay bars were places of territorial significance. One participant said:

We claim as our own and have a sense of pride that we [gay people] have this place. (P1)

In other instances, gay bars were places participants avoided because of undesirable activities taking place there, such as drug use or sexual activities. One participant explained:

I don't go to [club name] because people are doing drugs and hooking up (P5),

and another individual succinctly described gay bars/clubs as:

Fun but not healthy. (P8)

Violence was described as a deterrent for socializing at bars/clubs:

I don't go to clubs, I got tired of people fighting, dangerous things can happen like fights, stabbings, mace getting sprayed, getting robbed." (P13)

More than one participant noted that the result of being under the influence of alcohol at bars/clubs and being with people that they did not regularly socialize with sometimes resulted in spontaneous sexual encounters and HIV risk (e.g., unprotected intercourse). One participant described the risk at gay bars this way:

A one-night stand or a quicky, there is no condom because there is no conversation, you don't know them; you just have sex. (P13)

Routines, Paths, and Disclosure-AA MSM disclosure varied in this study depending on socio-spatial contexts. We define disclosure in this paper as the extent to which social network members know about the participants' same sex behavior. Home and gay bars/clubs were social spaces where AA MSM disclosure was explicit. However, during the course of regular paths and routines, the main activities centered on work/classes, and explicit disclosure was not as prominent. This is not to say that co-workers or fellow students did not know that the participant had sex with men, but acts of disclosure were not mentioned as a 
part of activities along the path. One participant summarized this by stating: "Some of my co-workers know I have a male partner but to them I'm just [name] who works here" (P2).

In summary, HIV risk and MSM disclosure were generally constrained by paths shaped by employment/school, with structured activities that consumed much of the day and interactions with people and places that were not associated with HIV risk. Time-space paths were not risk-free, however. HIV risk was evident in places where participants participated in activities that were described as unhealthy, and where alcohol and interactions with unfamiliar people were dominant.

\section{Paths with less Routine - the role of unemployment}

Lack of employment was a factor that was associated with less structured or regular, paths and routines. The unemployed AA MSM in this sample described boredom, which dictated their desire to seek an activity or companionship. HIV risk was encountered along these paths. One participant explained:

I'm unemployed (past year) and I'm in the process of looking for work so I have a lot of time on my hands. My routine is that I get up and I shower and may go to [a community market place] for a couple of hours and hang out or I may go to my mom's. Being unemployed, I find out that when you are not working you tend to do things that you normally wouldn't do if you were working, like go to risky places like [public park known for sex encounters]. (P3)

One routine of a 31 year old unemployed male exemplifies how HIV risk and disclosure was embedded within his path:
I sleep at my brother's - its rare that I spend the night somewhere else. I wake up and get myself together, look at the newspaper to see if there are job sites or advertisements that are interesting. Get me a coffee and sit down and read the paper and from there I really don't have company in my brother's house like that because I don't want them to know that I deal with men - try to keep that confidential - so like I said I go for a walk like I might walk down to the [business district] to see what's down there and see if I can meet someone new. Sometimes I meet people and sometimes I don't - it depends.

Interviewer: Why do you go out to meet people?

For company - because I am bored. The [business district] is my number one spotits relaxing, its alot of people, different types of people, black, white, Mexican and I like the nationality of the different people - when I go there I usually meet someone so its like a hot spot for me and I am able to meet more people there.

Interviewer: How much time do you spend trying to meet people?

2-4.5 hours - not the whole day

Interviewer: If you meet someone what usually happens?

We walk around and talk and try to get to know each other. He tells me about himself about whether he is seeing someone - a lot of people try to invite me to their house, because I tell them I don't have no spot so maybe a motel or something so I try to find someone with their own spot - so if they do then I will come over. (P20)

Routines, Paths, and Disclosure-Same sex behavior disclosure among these participants ranged from full disclosure (including kin) to no explicit disclosure. Paths of men who did not disclose MSM behavior were structured to avoid disclosure to family, 
friends and female sex partners. These men avoided places based on their desire to evade associations with MSM behavior. A participant explained:

I like to keep things separate, separate and easy. I don't venture out of my neighborhood unless I am going to [male partner's house]. I am more personal with my business [sex with men]; no one in my family knows. I don't go anywhere with [male partner]. I don't walk the street with him. (P18)

\section{Paths with less Routine - the role of addiction}

The daily time-space paths of men who were addicted to drugs or alcohol were dictated by their need to generate income to support their addiction, and to find places of escape and acceptance. In terms of the central role of addiction, an older participant stated:

I wake up and try to find some money for drugs and end up with other people looking for drugs or money. There's no routine, I go to where the drugs are best and sometimes will go to my associate's house to get high with him or go back home. (P14)

In terms of places of escape, home or a family member's home enabled participants to unwind and "get out of the rat race and get some peace and close everything out" (P14).

Risk was contingent upon these paths, which included spending time in places such as areas known for sex exchange and drug markets (i.e., where drugs were sold). In effect, these paths facilitated HIV risk.

The only part of my day I'm at high risk is at night when I decide to go and get some money [to buy crack]. I go up to [specific district], they call it [the name of place] because that's where all of the male prostitutes are - so I already know if I go up in there I'm going to get some money. That I know. That's the only part of the day when my risk is high. I hang on the corner or walk around the perimeter. Cars roll up and check you out and if they try to deal with you they pull over. Everyone knows that's the high prostitution are - the police even know - walking there is risky - especially if you don't have a condom, then its risky because of your freedom because the police can snatch you real fast, then its risky because of your reputation because its right off of [street] and some of your homies might be coming from the clubs and they might see you - there are a couple of risk factors.

Interviewer: All of this risk is contained in this one little perimeter that it sounds like you keep pretty separate from the rest of your life?

Yes I've been blessed to be able to keep it separate from the rest of my life - that's all it is I have been fortunate enough even though what I am doing is wrong as hell - I have been fortunate enough to keep that completely separated.

Interviewer: So if you stopped using crack would you still go there?

Nope, I mean that's real talk - Nope. (P10)

Paradoxically, while this sex exchange space was associated with HIV risk, two participants described it as a place where they felt safe and accepted:

We protect our own. (P10)

In [area known for sex trade], we can relate to each other, because people there are on the same page as me - they don't judge me for being out there because everyone is out there for the same reason - to hook up. (P7) 
For these men sex exchange spaces were both supportive and risky because sex exchange was normatively acceptable by individuals frequenting these places.

Routines, Paths, and Disclosure-Most of the men in this group openly disclosed their same sex behavior to their entire social network and described paths based on obtaining drugs and spending time in places known for male sex exchange without concern.

Two of the men in this group did not disclose to anyone in their social networks and they described themselves as "loners". However, they constructed their paths to evade people because of their shame related to their drug addiction. One participant stated,

\section{I don't like crowded areas like the mall or the market, I don't want to run into certain people because I'm ashamed for getting high (P14).}

\section{Discussion}

We sought to apply a time-geography perspective to explore the socio-spatial context of HIV risk among AA MSM. This study was limited by a small convenience sample, not intended to generalize to the Baltimore population of AA MSM or other MSM populations. Also, there was the possibility of bias in reporting behaviors, paths and routines during the interview. Men may have felt uncomfortable describing sexual behaviors (for example with co-workers) to the lead author and withheld information about places where sexual behavior occurred. However, even with these limitations, this study contributes to public health research and theorizing of socio-spatial dynamics by drawing upon complementary disciplines and theories to advance understanding of HIV risk in a population that is disproportionately affected. Findings revealed that (1) paths and routines were differentiated by employment and addiction, and (2) HIV risk was situated within social and spatial processes that included dimensions of MSM disclosure and substance use.

Employment is typically viewed by public health researchers as a variable to control for in statistical models predicting risk or outcomes. Results from this study revealed a sociospatial function of employment, that of imposing structure and form to time-space paths and routines, such that HIV risk was avoided or risk environments were excluded. These findings suggest developing programs that teach men to create regular paths and routines as a strategy to minimize HIV risk opportunities and risk environments. These skills could complement current behavioral approaches focused on proper condom use skills and HIV testing (Tobin et al. 2012).

In contrast to the work/school routines, which consumed much of the day for employed AA MSM and AA MSM who were currently students, routines and paths of both unemployed and addicted AA MSM were more flexible and risky. The lack of structured time and activities was related, for many of the unemployed AA MSM, with boredom, leading them to a search for companionship and interesting places (which often coincided with HIV risk). Consequently, these findings highlight the degree of time that these specific AA MSM have available to attend programs and their desire for engaging activities. One possibility is for programs to include meaningful planned activities, such as engaging in volunteer roles at community-based agencies (German, Latkin 2012), that might otherwise be spent in a risky setting. For example, men could assist AIDS service organizations with making risk reduction kits (e.g. condoms, lubricants and testing site information) to be distributed by street outreach workers or volunteer at local soup kitchens or recreation centers.

Consistent with extant literature on substance abusing MSM, addiction was associated with routines and paths that included spaces for sex exchange and drug use (Gorbach et al. 2009, Semple et al. 2010, Rietmeijer et al. 1998, Tobin, Latkin 2008). Results also suggest the 
importance of designing programs for addicted AA MSM that acknowledge their need for a place of escape or rest, where they can be accepted without normative support of substance use. One specific way in which this could be achieved is allowing men to come early to intervention sessions to relax and unwind from the stresses of their paths before beginning the substantive content of the program, which may optimize skills building.

Bars/clubs and sex exchange spaces, conventionally viewed by public health researchers as risk venues, were paradoxically described as having both positive and negative dimensions. These spaces provided social acceptance but also elevated HIV risk behaviors such as substance use and unsafe sex. The overlapping and contradictory elements within these social spaces underscores the complexity of how place shapes health and risk and discourages a monolithic view of any given venue or space as risky or safe (Takahashi and Magalog, 2008). Interventions that promote avoiding risk venues may have an unanticipated effect of denying AA MSM a source of social support and group affiliation. Providing AA MSM with the skills and resources to reduce risk within these environments may be a more effective approach.

In contrast, the spaces of home, employment, and school were not described by these participants as possible spaces of risk in similar ways as bars/clubs and sex exchange spaces. This could be because these participants idealized these spaces as "safe" or "controlled" because other spaces were relatively more risky or dangerous. Spaces, such as home and informal gathering places that foster "sociability," enabled men to socialize with their friends/kin and access social support (Glover, Parry 2009, Oldenburg 2003, Duff 2011). This finding confirms the enabling spaces literature, which points to socio-spatial environments that may be more conducive to HIV prevention efforts, such as those where individuals feel safe, are in control, and have an enhanced sense of self where they are not distracted so that they may focus on the prevention messages (Downing et al. 2001, Ross, Williams 2002). For clinic-based interventions this emphasizes the value of designing the space to emulate or reproduce the safety and control of "home". Another possibility would be to design programs that could be delivered in a home environment such as a web-based program or video series that teaches skills and generates discussion with friends and partners. AA MSM would be able to control when they engage with the program and with whom they would want to share the program. More research is needed to unpack spaces of home, employment, and school for their risk or prevention potentials for AA MSM.

We observed evidence that MSM disclosure was temporally, spatially and socially contingent (Berg, Longhurst 2003). Some AA MSM daily routines and paths were constructed to include places where disclosure was explicit, such as gay bars/clubs and areas known for male sex work. However, many men compartmentalized their paths, activities and social interactions to avoid unwanted explicit MSM disclosure. This compartmentalization is similar to findings from a study by Frye et al (2006), which highlights the role of urban neighborhoods in shaping identity. Specifically, she notes how movement between neighborhoods modifies behavior and expression of identity. There are limited and mixed findings on the association between non-disclosure of same sex behavior and HIV risk among AA MSM (Millett et al. 2005, Wolitski et al. 2006). AA MSM are more likely to identify as bisexual (Williams et al. 2009, Harawa et al. 2008) and are more reluctant to disclose their sexual behavior to others compared to White MSM (Millett et al. 2005, Kennamer et al. 2000, McKirnan et al. 1995, Stoke, Vanable \& McKirnan 1996, Kraft et al. 2000, Jimenez 2003, Wheeler 2006, Stokes, Peterson 1998). Researchers have consequently examined AA MSM who have not disclosed their same sex behavior, using terms such as "down low" and non-gay identified interchangeably with sexual identity and disclosure categories, however, these terms have not corresponded to the same set of behaviors and cognitions across studies (Millett et al. 2005, Wolitski et al. 2006, Pathela et 
al. 2006). There are a number of implications from these findings in terms of clarifying a socio-spatial context of disclosure. First, the findings challenge the conceptualization of the role of disclosure and/or sexual identity as static risk or protective factor. As disclosure and identity are variably structured and practiced over time and space, it may be more appropriate to shift to thinking about multiple and contingent disclosures and identities (Berg, Longhurst 2003, Del Casino Jr. 2007, Thien, Del Casino 2012), and therefore, designing interventions that acknowledge this context and include content that adapts to men's daily routines. Results from this study support expanding study design, by devising and testing measurement to incorporate social, temporal and spatial dimensions of health and behavior (Cutchin 2007) to advance our ability to clarify the causal factors for disparities and to develop effective public health responses.

\section{REFERENCE LIST}

Berg LD, Longhurst R. Placing Masculinities and Geography. Gender, Place \& Culture. 2003; vol. 10(no. 4):351-360.

Centers for Disease Control and Prevention. Sexually Transmitted Disease Surveillance 2010. Atlanta: U.S.: Department of Health and Human Services; 2011.

Centers for Disease Control and Prevention. Tracking the Hidden Epidemics: Trends in STDs in the United States 2000. 2000.

Colfax G, Coates TJ, Husnik MJ, Huang Y, Buchbinder S, Koblin B, Chesney M, Vittinghoff E. EXPLORE Study Team. Longitudinal patterns of methamphetamine, popper (amyl nitrite), and cocaine use and high-risk sexual behavior among a cohort of san francisco men who have sex with men. Journal of urban health : bulletin of the New York Academy of Medicine. 2005; vol. 82 Suppl 1(no. 1):i62-i70. [PubMed: 15738319]

Crosby GM, Stall RD, Paul JP, Barrett DC, Midanik LT. Condom use among gay/bisexual male substance abusers using the timeline follow-back method. Addictive Behaviors. 1996; vol. 21(no. 2):249-257. [PubMed: 8730528]

Cutchin MP. The need for the "new health geography" in epidemiologic studies of environment and health. Health \& place. 2007; vol. 13(no. 3):725-742. [PubMed: 17208033]

Del Casino VJ Jr. Flaccid theory and the geographies of sexual health in the age of Viagra ${ }^{\mathrm{TM}}$. Health \& place. 2007; vol. 13(no. 4):904-911. [PubMed: 17382575]

Downing M, Knight K, Reiss TH, Vernon K, Mulia N, Ferreboeuf M, Carroll A, Vu C. Drug users talk about HIV testing: motivating and deterring factors. AIDS Care. 2001; vol. 13(no. 5):561-577. [PubMed: 11571004]

Duff C. Networks, resources and agencies: On the character and production of enabling places. Health \& place. 2011; vol. 17(no. 1):149-156. [PubMed: 20926330]

Egan JE, Frye V, Kurtz SP, Latkin C, Chen M, Tobin K, Yang C, Koblin BA. Migration, neighborhoods, and networks: approaches to understanding how urban environmental conditions affect syndemic adverse health outcomes among gay, bisexual and other men who have sex with men. AIDS and behavior. 2011; vol. 15(Suppl 1):S35-S50. [PubMed: 21369730]

Finlayson T, Le B, Smith A, Bowles K, Cribbin M, Miles I, Oster A, Martin T, Edwards A, DiNenno E. HIV Risk, Prevention, and Testing Behaviors Among Men Who Have Sex With Men--National HIV Behavioral Surveillance System, 21 U.S. Cities, United States 2008. MMWR Surveillance Summaries. 2011; vol. 60(no.-14):1-38.

Frye V, Latka MH, Koblin B, Halkitis PN, Putnam S, Galea S, Vlahov D. The urban environment and sexual risk behavior among men who have sex with men. Journal of urban health : bulletin of the New York Academy of Medicine. 2006; vol. 83(no. 2):308-324. [PubMed: 16736379]

German D, Latkin CA. Boredom, Depressive Symptoms, and HIV Risk Behaviors Among Urban Injection Drug Users. AIDS and behavior. 2012

German D, Sifakis F, Maulsby C, Towe VL, Flynn CP, Latkin CA, Celentano DD, Hauck H, Holtgrave DR. Persistently high prevalence and unrecognized HIV infection among men who have sex with men in Baltimore: the BESURE Study. Journal of acquired immune deficiency syndromes (1999). 2011; vol. 57(no. 1):77-87. [PubMed: 21297479] 
Gilbert MR. "Race," Space, and Power: The Survival Strategies of Working Poor Women. Annals of the Association of American Geographers. 1998; vol. 88(no. 4):595-621.

Glover TD, Parry DC. A third place in the everyday lives of people living with cancer: Functions of Gilda's Club of Greater Toronto. Health \& place. 2009; vol. 15(no. 1):97-106. [PubMed: 18417414]

Gorbach PM, Murphy R, Weiss RE, Hucks-Ortiz C, Shoptaw S. Bridging sexual boundaries: men who have sex with men and women in a street-based sample in Los Angeles. Journal of urban health : bulletin of the New York Academy of Medicine. 2009; vol. 86 Suppl 1(no. 1):63-76. [PubMed: 19543837]

Harawa NT, Williams JK, Ramamurthi HC, Manago C, Avina S, Jones M. Sexual behavior, sexual identity, and substance abuse among low-income bisexual and non-gay-identifying African American men who have sex with men. Archives of Sexual Behavior. 2008; vol. 37(no. 5):748762. [PubMed: 18546069]

Jacobson J. The dismantling of Baltimore's public housing:Housing Authority cutting 2,400 homes for the poor from its depletedinventory - A15-year trend shows a decrease of 42 percent in occupied units. 2007

Jimenez AD. Triple jeopardy: targeting older men of color who have sex with men. Journal of acquired immune deficiency syndromes (1999). 2003; vol. 33(Suppl 2):S222-S225. [PubMed: 12853872]

Kennamer JD, Honnold J, Bradford J, Hendricks M. Differences in disclosure of sexuality among African American and White gay/bisexual men: implications for HIV/AIDS prevention. AIDS Education and Prevention : Official Publication of the International Society for AIDS Education. 2000; vol. 12(no. 6):519-531. [PubMed: 11220504]

Koblin BA, Husnik MJ, Colfax G, Huang Y, Madison M, Mayer K, Barresi PJ, Coates TJ, Chesney MA, Buchbinder S. Risk factors for HIV infection among men who have sex with men. AIDS (London, England). 2006; vol. 20(no. 5):731-739.

Kraft JM, Beeker C, Stokes JP, Peterson JL. Finding the "community" in community-level HIV/AIDS interventions: formative research with young African American men who have sex with men. Health education \& behavior : the official publication of the Society for Public Health Education. 2000; vol. 27(no. 4):430-441.

Magnus M, Kuo I, Phillips G, Shelley K, Rawls A, Montanez L, Peterson J, West-Ojo T, Hader S, Greenberg AE. Elevated HIV prevalence despite lower rates of sexual risk behaviors among black men in the District of Columbia who have sex with men. AIDS Patient Care and STDs. 2010; vol. 24(no. 10):615-622. [PubMed: 20863246]

McKirnan DJ, Stokes JP, Doll L, Burzette RG. Bisexually Active Men: Social Characteristics and Sexual Behavior. Journal of sex research. 1995; vol. 32(no. 1):65-76.

Millett G, Malebranche D, Mason B, Spikes P. Focusing "down low": bisexual black men, HIV risk and heterosexual transmission. Journal of the National Medical Association. 2005; vol. 97(no. 7 Suppl):52S-59S. [PubMed: 16080458]

Millett GA, Flores SA, Peterson JL, Bakeman R. Explaining disparities in HIV infection among black and white men who have sex with men: a meta-analysis of HIV risk behaviors. AIDS (London, England). 2007; vol. 21(no. 15):2083-2091.

Mills TC, Stall R, Pollack L, Paul JP, Binson D, Canchola J, Catania JA. Health-related characteristics of men who have sex with men: a comparison of those living in "gay ghettos" with those living elsewhere. American Journal of Public Health. 2001; vol. 91(no. 6):980-983. [PubMed: 11392945]

Mimiaga MJ, Reisner SL, Fontaine YM, Bland SE, Driscoll MA, Isenberg D, Cranston K, Skeer MR, Mayer KH. Walking the line: stimulant use during sex and HIV risk behavior among Black urban MSM. Drug and alcohol dependence. 2010; vol. 110(no. 1-2):30-37. [PubMed: 20334986]

Oldenburg, R. Third Places. In: Christensen, K.; Levinson, D., editors. Encyclopedia of Community: From the Village to the Virtual World. 1st edn. SAGE; 2003. p. 373-376.

Pathela P, Hajat A, Schillinger J, Blank S, Sell R, Mostashari F. Discordance between sexual behavior and self-reported sexual identity: a population-based survey of New York City men. Annals of Internal Medicine. 2006; vol. 145(no. 6):416-425. [PubMed: 16983129] 
Pred, A. Economic Geography. Vol. vol. 53. Planning-Related Swedish Geographic Research; 1977a. The Choreography of Existence: Comments on Hägerstrand's Time-Geography and Its Usefulness; p. 207-221.

Pred, A. City-Systems in Advanced Economies: Past Growth, Present Processes, and Future Development. New York City: Wiley; 1977b.

Reisner SL, Mimiaga MJ, Bland S, Skeer M, Cranston K, Isenberg D, Driscoll M, Mayer KH. Problematic alcohol use and HIV risk among Black men who have sex with men in Massachusetts. AIDS Care. 2010; vol. 22(no. 5):577-87. [PubMed: 20336557]

Rhodes F, Deren S, Wood MM, Shedlin MG, Carlson RG, Lambert EY, Kochems LM, Stark MJ, Falck RS, Wright-DeAguero L, Weir B, Cottler L, Rourke KM, Trotter RT 2nd. Understanding HIV risks of chronic drug-using men who have sex with men. AIDS Care. 1999; vol. 11(no. 6): 629-648. [PubMed: 10716005]

Rhodes T. Risk environments and drug harms: a social science for harm reduction approach. The International journal on drug policy. 2009; vol. 20(no. 3):193-201. [PubMed: 19147339]

Rietmeijer CA, Wolitski RJ, Fishbein M, Corby NH, Cohn DL. Sex hustling, injection drug use, and non-gay identification by men who have sex with men: Associations with high-risk sexual behaviors and condom use. Sexually transmitted diseases. 1998; vol. 25(no. 7):353-360. [PubMed: 9713915]

Ross MW, Williams ML. Effective Targeted and Community HIV/STD Prevention Programs. Journal of sex research. 2002; vol. 39(no. 1):58-62. [PubMed: 12476258]

Semple SJ, Strathdee SA, Zians J, Patterson TL. Social and behavioral characteristics of HIV-positive MSM who trade sex for methamphetamine. The American Journal of Drug and Alcohol Abuse. 2010; vol. 36(no. 6):325-331. [PubMed: 20955106]

Sifakis F, Hylton JB, Flynn C, Solomon L, MacKellar DA, Valleroy LA, Celentano DD. Prevalence of HIV infection and prior HIV testing among young men who have sex with men. The Baltimore young men's survey. AIDS and behavior. 2010; vol. 14(no. 4):904-912. [PubMed: 17968648]

Sifakis F, Hylton JB, Flynn C, Solomon L, Mackellar DA, Valleroy LA, Celentano DD. Racial disparities in HIV incidence among young men who have sex with men: the Baltimore Young Men's Survey. Journal of acquired immune deficiency syndromes (1999). 2007; vol. 46(no. 3): 343-348. [PubMed: 17846561]

Stall R, Mills TC, Williamson J, Hart T, Greenwood G, Paul J, Pollack L, Binson D, Osmond D, Catania JA. Association of co-occurring psychosocial health problems and increased vulnerability to HIV/AIDS among urban men who have sex with men. American Journal of Public Health. 2003; vol. 93(no. 6):939-942. [PubMed: 12773359]

Stoke JP, Vanable PA, McKirnan DJ. Ethnic Differences in Sexual Behavior, Condom Use, and Psychosocial Variables among Black and White Men Who Have Sex with Men. Journal of sex research. 1996; vol. 33(no. 4):373-381.

Stokes JP, Peterson JL. Homophobia, self-esteem, and risk for HIV among African American men who have sex with men. AIDS Education and Prevention : Official Publication of the International Society for AIDS Education. 1998; vol. 10(no. 3):278-292. [PubMed: 9642425]

Takahashi LM, Magalong MG. Disruptive social capital: (un)healthy socio-spatial interactions among Filipino men living with HIV/AIDS. Health \& place. 2008; vol. 14(no. 2):182-197. [PubMed: 17658287]

Thien D, Del Casino VJ. (Un)Healthy 1 Men, Masculinities, and the Geographies of Health. Annals of the Association of American Geographers. 2012; vol. 102(no. 5):1146-1156.

Tobin KE, Kuramoto SJ, German D, Fields E, Spikes P, Patterson J, Latkin C. Unity in Diversity: Results of a randomized clinical culturally tailored pilot HIV prevention intervention trial in Baltimore, MD, for African American men who have sex with men. Health Educ Behav. 2012

Tobin KE, Latkin CA. An examination of social network characteristics of men who have sex with men who use drugs. Sexually transmitted infections. 2008; vol. 84(no. 6):420-424. [PubMed: 19028939]

U.S. Census Bureau. State and county quick facts. Baltimore City, MD: 2012. Available: http:// quickfacts.census.gov/qfd/states/24/24510.html [2012, 10, 08]. 
Wheeler DP. Exploring HIV prevention needs for nongay-identified black and African American men who have sex with men: a qualitative exploration. Sexually transmitted diseases. 2006; vol. 33(no. 7 Suppl):S11-S16. [PubMed: 16614589]

Williams C, Mackesy-Amiti M, McKirnan D, Ouellet L. Differences in Sexual Identity, Risk Practices, and Sex Partners between Bisexual Men and Other Men among a Low-Income DrugUsing Sample. Journal of Urban Health. 2009; vol. 86:93-106. [PubMed: 19479381]

Wolitski RJ, Jones KT, Wasserman JL, Smith JC. Self-Identification as "Down Low" among Men Who Have Sex with Men (MSM) from 12 US Cities. AIDS and Behavior. 2006; vol. 10(no. 5): 519-529. [PubMed: 16691462]

Zisberg A, Young HM, Schepp K, Zysberg L. A concept analysis of routine: relevance to nursing. Journal of advanced nursing. 2007; vol. 57(no. 4):442-453. [PubMed: 17291208] 


\section{Highlights}

- We explore daily routines and paths to examine how social and spatial environments shape HIV risk.

- Findings revealed paths and routines were differentiated by employment and addiction.

- Findings suggest need for investigations of HIV risk behavior within sociospatial settings. 
Table 1

Participant Characteristics

\begin{tabular}{|c|c|c|}
\hline Regular and planned paths/routines & $\begin{array}{l}\text { Paths with less routine: } \\
\text { unemployment }\end{array}$ & $\begin{array}{l}\text { Paths with less routine: } \\
\text { addiction }\end{array}$ \\
\hline $\begin{array}{ll}\text { - } & \text { P1: aged 22, full-time student } \\
\text { - } & \text { P2: aged 49, part-time employ } \\
\text { - } & \text { P4: aged <30, full time employ } \\
\text { - } & \text { P5: aged 21, full time employ } \\
\text { - } & \text { P6: aged 28, part-time employ } \\
\text { - } & \text { P9: aged 44, part-time employ } \\
\text { - } & \text { P12: aged 30, full time employ } \\
\text { - } & \text { P13: aged 27, full time employ } \\
\text { - } & \text { P16: aged 21, full time employ } \\
\text { - } & \text { P 19: aged 29, employed }\end{array}$ & $\begin{array}{l}\text { - } \\
\text { P3: aged 39; unemployed } \\
\text { - } \quad \text { P8: aged 22, unemployed } \\
\text { P 18: aged 43, } \\
\text { unemployed, P 20: aged } \\
\text { 31, unemployed }\end{array}$ & $\begin{array}{l}\text { P7: aged 26, unemployed, alcohol and } \\
\text { marijuana } \\
\text { - } \quad \text { P10: aged 40, not working, crack \& heroin } \\
\text { use } \\
\text { - } \quad \text { P11: aged 32, unemployed, crack use } \\
\text { - } \quad \text { P14: aged 50, unemployed, heroin \& } \\
\text { alcohol use } \\
\text { - P15: aged 50, not working, crack use } \\
\text { P17: aged 47, not working, crack use }\end{array}$ \\
\hline
\end{tabular}

